Комплиментарность научной, учебной и внеучебной деятельности студентов, представленная на Рисунке 1. приводит к формированию универсальнылх учебных действий, что в свою очередь приводит к формированию (освоению) ими компетенций.

Модель комплиментарности позволяет уточнить механизм интегративных процессов в научной, учебной и внеучебной деятельности субъектов образовательного процесса в среде вуза, отразить существующие между ними функциональные связи, которые придают формирующе-развивающей среде вуза устойчивость, целостность и достаточно высокую результативность.

$$
* * *
$$

1. Ени В.В. Теоретические и праксиологические основы формирующе-развивающей среды вуза в контексте интеграции научной, учебной и внеучебной деятельности /дисс...д.п.н. / В.В. Ени. Кишинев, 2017. - 348 с.

2. Пирогов Н.И. Вопросы жизни. Избранные педагогические сочинения. Москва: Педагогика, 1985. $496 \mathrm{c}$.

3. Управление образовательными системами. Под ред. Т.И. Шамовой. Москва: Владос, 2001. 320 с.

4. Шамова Т.И. Управление образовательными системами. Москва: ВЛАДОС, 2001. 320 с.

\title{
Заводчикова М.Б., Черемхина А.П. \\ Своевременные инженерно-геотехнические изыскания (ИГС) как залог безопасной и качественной реконструкции и нового строительства в условиях городской застройки
}

Санкт-Петербургский государственный архитектурно-строительный университет

doi: $10.18411 / \mathrm{sr}-10-04-2021-45$

(Россия, Санкт-Петербург)

\section{Аннотация}

В статье описаны основные виды работ при инженерно-геологических и инженерно-геотехнических изысканиях на этапе реконструкции зданий. В качестве примера рассмотрена реконструкция административного здания, являвшегося ранее производственным корпусов фабрики.

Ключевые слова: инженерно-геологические изыскания, инженерногеотехнические изыскания, реконструкция, мониторинг, инженерные изыскания, стадии инженерно-геологических изысканий.

\section{Abstract}

The article describes the main types of work in engineering, geological and engineering and geotechnical research during the reconstruction phase of buildings. As an example, the reconstruction of the administrative building, which was formerly the factory's production building, was considered.

Keywords: engineering and geological research, engineering and geotechnical research, reconstruction, monitoring, engineering research, stages of engineering and geological research.

Любому проектированию, строительству и реконструкции зданий и сооружений в обязательном порядке предшествуют инженерные изыскания, которые в свою очередь включают инженерно-геологические, инженерно-геотехнические, инженерногидрогеологические, инженерно-экологические и инженерно-геодезические изыскания.

Инженерно-геологические изыскания (ИГИ), являющиеся основой инженерных изысканий, выполняются в соответствии с требованиями ряда нормативных документов -СП 47.13330.2016, СП 11-105-97 и СП 446.1325800.2019. Организованы ИГИ могут быть на любой стадии проектирования, строительства и эксплуатации 
зданий и сооружений. Любой строительно-инвестиционный цикл, подразумевает непрерывное взаимодействие изыскателей, проектировщиков и строителей, что является необходимым для безаварийного строительства и дальнейшей эксплуатации зданий и сооружений.

Согласно СП 446.1325800.2019, введенном в действие 06.12.2019, инженерногеологические изыскания состоят из: изысканий для подготовки документов территориального планирования, планировки территории и выбора площадок (трасс) строительства (обоснования инвестиций), первого и второго этапа для подготовки проектной документации, и изысканий при строительстве и реконструкции зданий и сооружений.[6]

На каждом из этапов инженерно-геологических изысканий решается определенный набор задач, так на этапе реконструкции, где основными видами изысканий являются инженерно-геологические и инженерно-геотехнические исследования, к основным задачам можно отнести изучение изменения инженерногеологических условий в период эксплуатации и определение категории технического состояния реконструируемого здания соответственно.

Реконструкция зданий и сооружений, т.е. комплекс строительных работ, направленный на изменение основных технико-экономических показателей, таких как изменение нагрузок, планировки и площади помещений, выполняется в первую очередь в зависимости от назначения самого здания, например, переквалификация здания под другие нужды, устаревание, полная или частичная потеря функциональности одной или нескольких инженерных систем (отопительная, светотехническая, вентиляционная и тд) или конструктива здания.[4]

Основной целью при реконструкции промышленных зданий и сооружений является модернизация.[2] Реконструкция в данном случае направлена на усовершенствование применяемых технологий, увеличение числа используемых устройств или монтаж нового оборудования.[4]

Реконструкции жилой застройки имеет другие цели, в первую очередь это увеличение полезной площади помещения и преобразование архитектурного облика здания. Увеличение полезной площади здания за счет осуществления строительно монтажных работ, предполагает добавление пристроек, надстроек или возведение мансардного этажа. Может также возникать необходимость в укреплении несущих конструкций, восстановлении кирпичной кладки и наращивании цоколя.[4]

В зависимости от назначения и уровня ответственности здания, целей реконструкции, а также от категории сложности грунтовых условий программа инженерно-геологических изысканий в рамках этапа реконструкции может существенно отличаться.

Так изучение инженерно-геологических условий на этапе реконструкции включает в себя - определение изменения рельефа, геологического строения, гидрогеологических условий, состава, состояния и свойств грунтов, активности инженерно-геологических процессов.[5,6]

В условиях плотной городской застройки строительство вновь возводимых зданий оказывает негативное влияние на основания, фундаменты и надземные конструкции уже существующих зданий, в таком случае увеличиваются объемы работ по реконструкции зданий, попавших в зону влияния нового строительства.

Проектирование реконструкций таких зданий требуют особого подхода к проводимым инженерно-геологическим и инженерно-геотехническим изысканиям, техническому обследованию подземных и наземных конструкций зданий, а также систем инженерных коммуникаций. [3]

При инженерно-геотехнических изысканиях, основной целью которых и является изучение взаимодействия модели фундамент - грунтовый массив, основными 
работами будут являться - обследование основания, фундамента и надземных строительных конструкций реконструируемого здания или сооружения. В период строительства, эксплуатации и реконструкции здания в состав инженерногеотехнических изысканий может быть включен геотехнический мониторинг.

Результатом данных обследований является получение информации о прочности фундамента, НДС состоянии грунтов основания и надземных конструкций. Обследование технического состояния здания осуществлялось в соответствии с ГОСТ 31397-2011, СП 13-102 2003, СРП- 2007, ТСН 50-302-2004.

Переходя от общего к частному, рассмотрим выполнение реконструкции на примере здания, являющиеся объектом культурного наследия и представляющие собой историко-архитектурную ценность, как яркий образец фабричной архитектуры начала $\mathrm{XX}$ века с элементами неоклассики. Объект реконструкции, находящийся на территории бывшей макаронной фабрики, построен в начале XX века и по своему функциональному назначению являлось производственным корпусом.

Обследования с целью дальнейшей реконструкции впервые были выполнены в 2009 году, тогда было определено техническое состояние и пригодность к дальнейшей эксплуатации основания, фундаментов и стен здания, а также разработаны рекомендация по осуществлению мероприятий, необходимых для стабилизации деформаций здания. В ходе данного обследования были установлены глубины заложения фундаментов продольных и торцевых несущих стен. Данные, полученные в ходе данных изысканий, легли в основу дальнейшей реконструкции здания, выполненной в период с 2011 по 2013 г с целью приспособления объекта для современного использования в качестве офисного здания.

В ходе выполненных инженерно-геологических и инженерно-геотехнических изысканий состояние стен оценивалось как ограниченно-работоспособное, выявлены трещины шириной раскрытия $1 \ldots 20$ мм, причинами развития которых могла служить неравномерная загрузка перекрытий в процессе эксплуатации или неравномерная осадка основания, ввиду наличия слабого подстилающего слоя (ИГЭ 3) значительной мощности (рис.5). Состояние фундаментов также признано ограниченноработоспособным. В обследовании произведен сбор нагрузок и расчет фундаментов по осям "А", Б", "В" на существующие нагрузки до начала приспособления здания (рис.1,2 ). Данный расчет показал не выполнение условия первого предельного состояния для основания фундаментов под несущими продольными наружными стенами и внутреннего продольными столбами, что являлось основанием для усиления основания фундаментов.

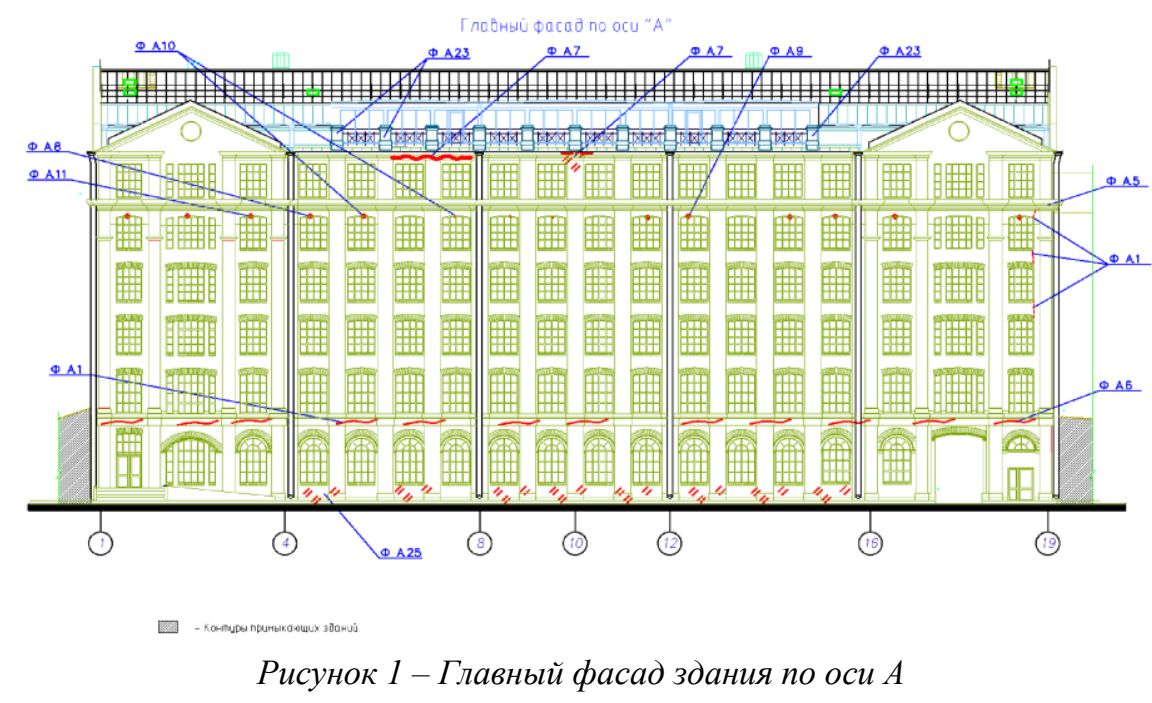




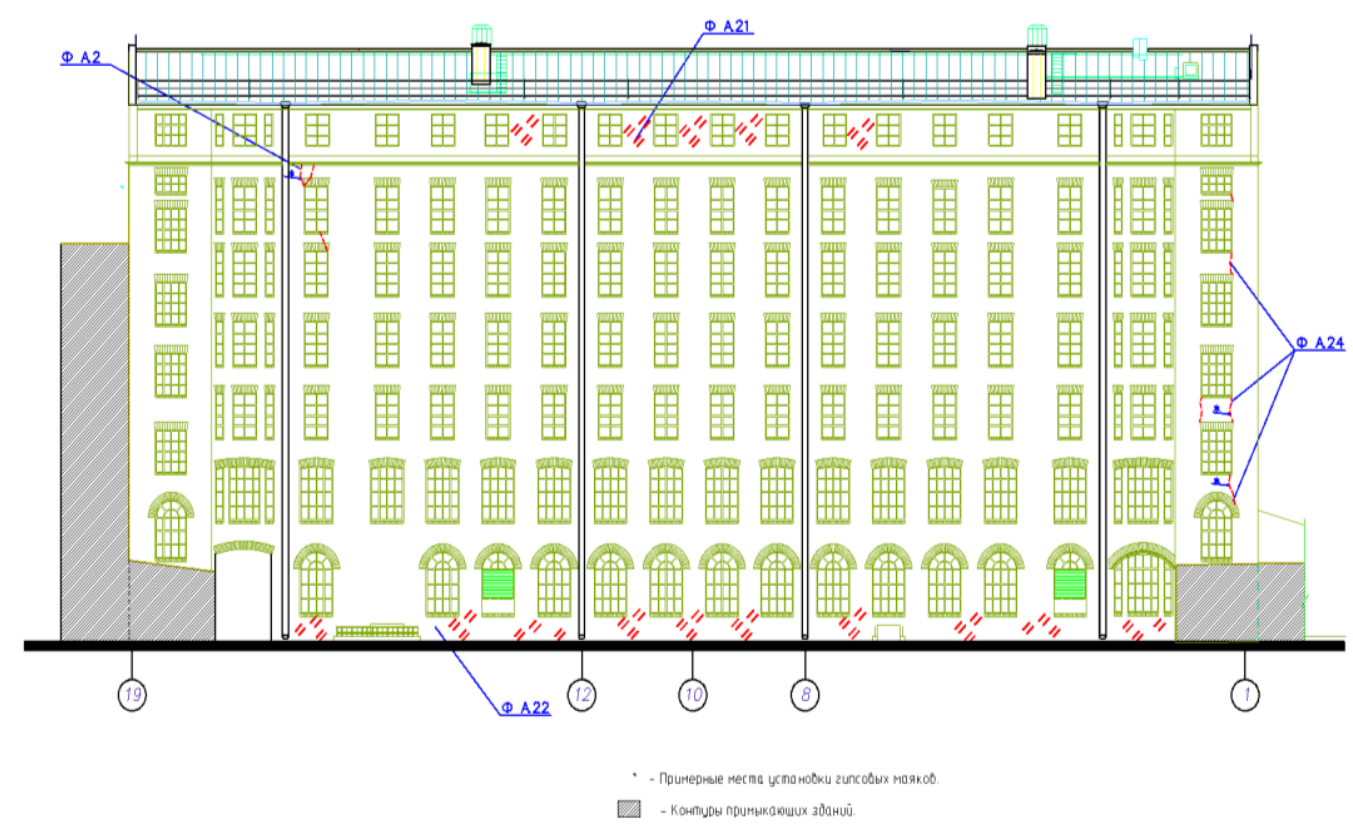

Рисунок 2- Дворовой фасад здания по оси B

На основании полученных в ходе инженерно-геологических и инженерногеотехнических изысканий данных, в 2011-2013 годах были выполнены работы по реконструкции здания, а именно: понижение уровня пола подвала с устройством ж/б кессона между осями А-B/2-17, высотой 2.4 м, связанными с существующими ленточными фундаментами, усилены основания с помощью устройства микросвай и скважин уплотнения грунта, вместо чердака была устроена мансарда, заменены аварийные элементы конструкций, выполнены работы по устройству новых монолитных ж/б перекрытий над подвалом и шестым этажом и ремонту ж/б перекрытий 1-5 этажей, выполнено строительство новых лифтовых шахт и установка двух грузовых лифтов, монтаж систем отопления, вентиляции, холодного и горячего водоснабжения.

Мероприятия по усилению грунтов основания с помощью устройства микросвай и скважин уплотнения грунта практически стабилизировали неравномерные осадки здания.

Дополнительные инженерно-геологические изыскания и обследование здания бизнес-центра повторно были выполнены в 2019 году с целью определения необходимых мероприятий для обеспечения безопасной эксплуатации здания бизнесцентра.

В рамках изысканий были пробурены и опробованы 2 скважины, выполнено статическое зондирование в 2-х точках (рис.3, 4 ), а также инженерно-геодезические работы по измерению кренов здания и лабораторные исследования грунтов. При инженерно-геотехнические изысканиях - техническое обследование здания с фотофиксацией имеющихся дефектов и повреждений, сравнение выявленных дефектов с архивными материалами по обследованиям, а также сбор нагрузок и поверочные расчеты фундаментов. В заключении были даны рекомендации по стабилизации деформаций и дальнейшей безаварийной эксплуатации здания. Результаты, полученные в рамках данных дополнительных изысканий, полностью подтвердили результаты, полученные ранее, в ходе исследований 2009 года. В частности, данные бурения и статического зондирования подтвердили наличие слабого подстилающего слоя мощностью от 2,5 до 6 м, наличие которого уменьшает несущую способность грунта основания. 


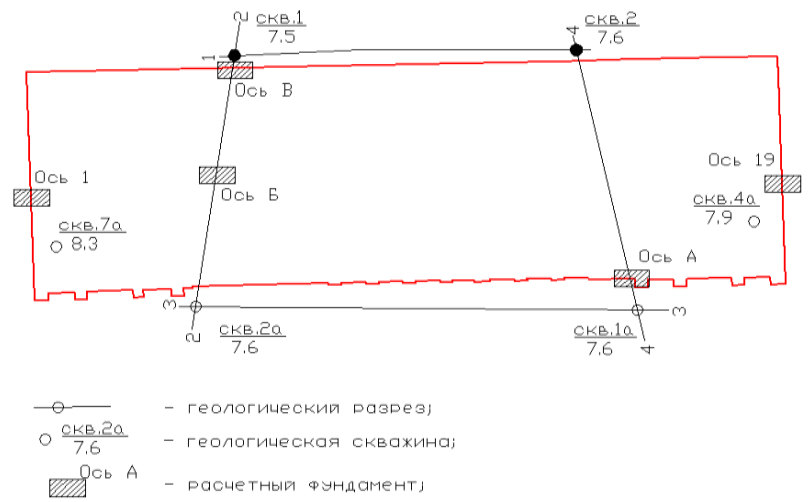

Рисунок 3- Схема расположения инженерно-геологических выработок

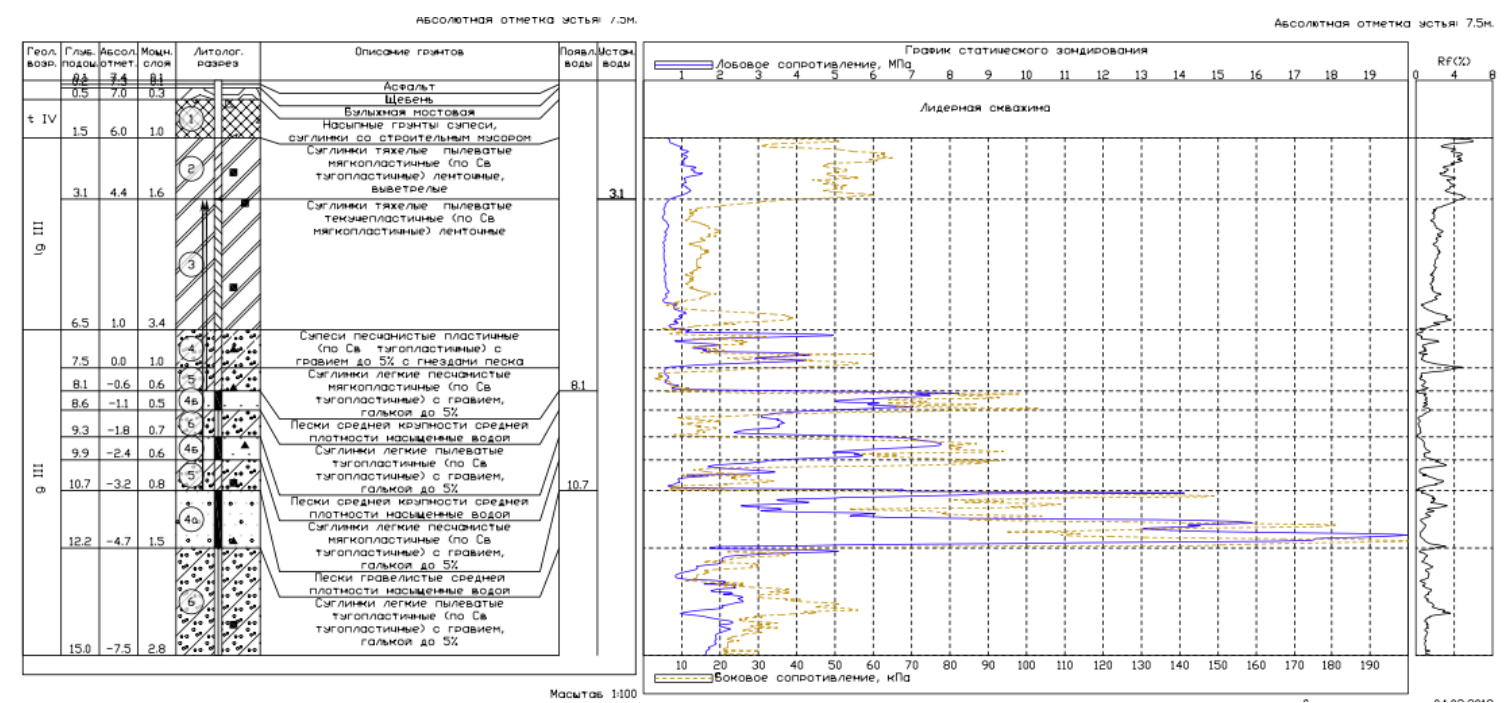

Рисунок 4 - Колонка скважин, совмещенная с графиком статического зондирования
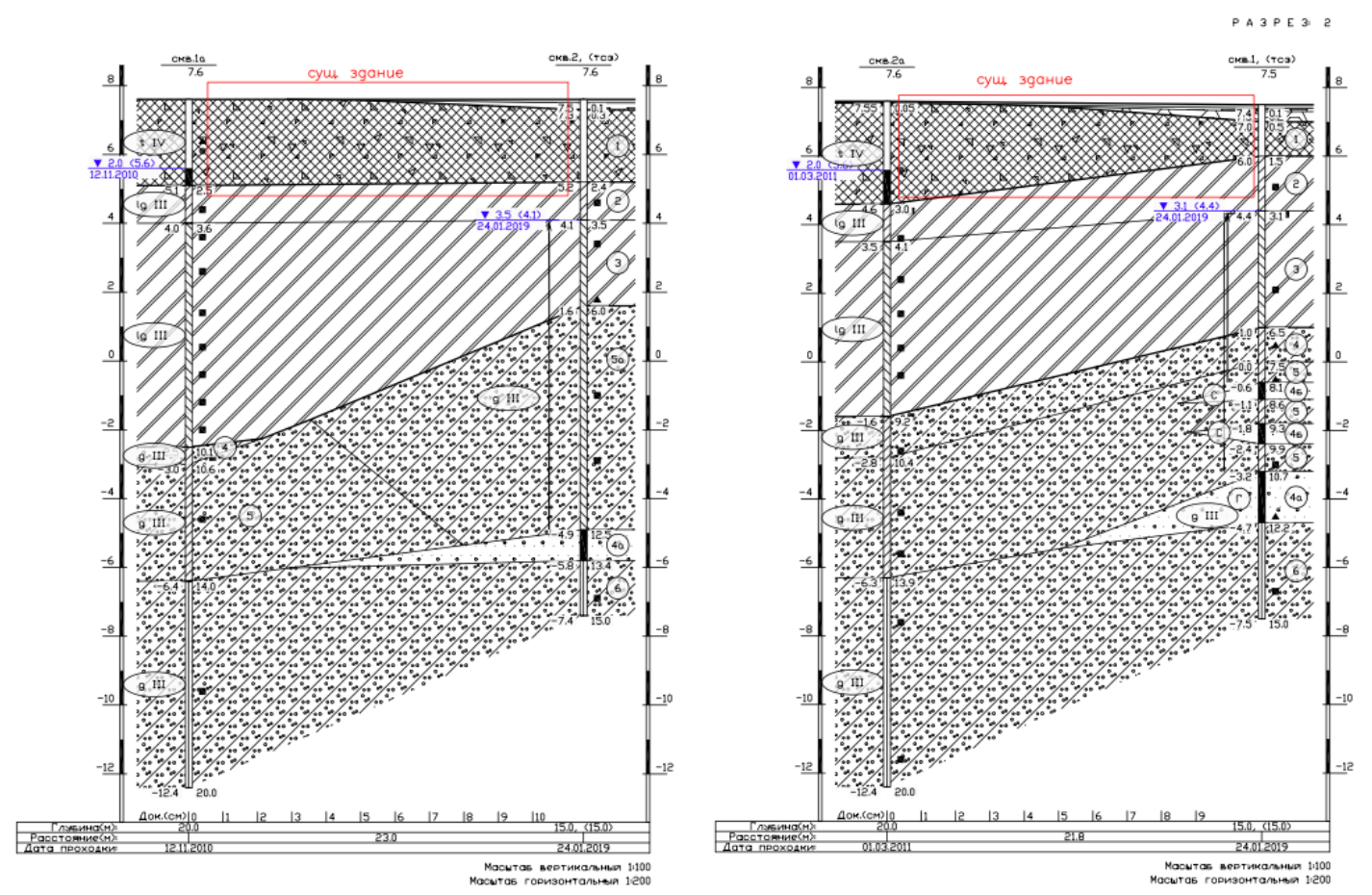

Рисунок 5 - Инженерно - гелогические разрезы по линии скв.1 1 - скв. 2 и по линии скв. $2 a$ - скв. 1

В процессе обследования в стене обнаружена вертикальная трещина, шириной раскрытия до 2 мм осях 19/Б-В, следы замачивания, отслоение окрасочного и 
декоративного слоев кирпичной кладки фасадов (рис.6, 7). Причиной возникновения трещины названа неравномерная осадка фундаментов.

Опасных дефектов для дальнейшей эксплуатации здания не обнаружено. В целом техническое состояние стен может быть охарактеризовано работоспособное, за исключением участка наружной стены в осях 19/Б-В, находящегося в ограниченноработоспособном состоянии (рис.6, 7)

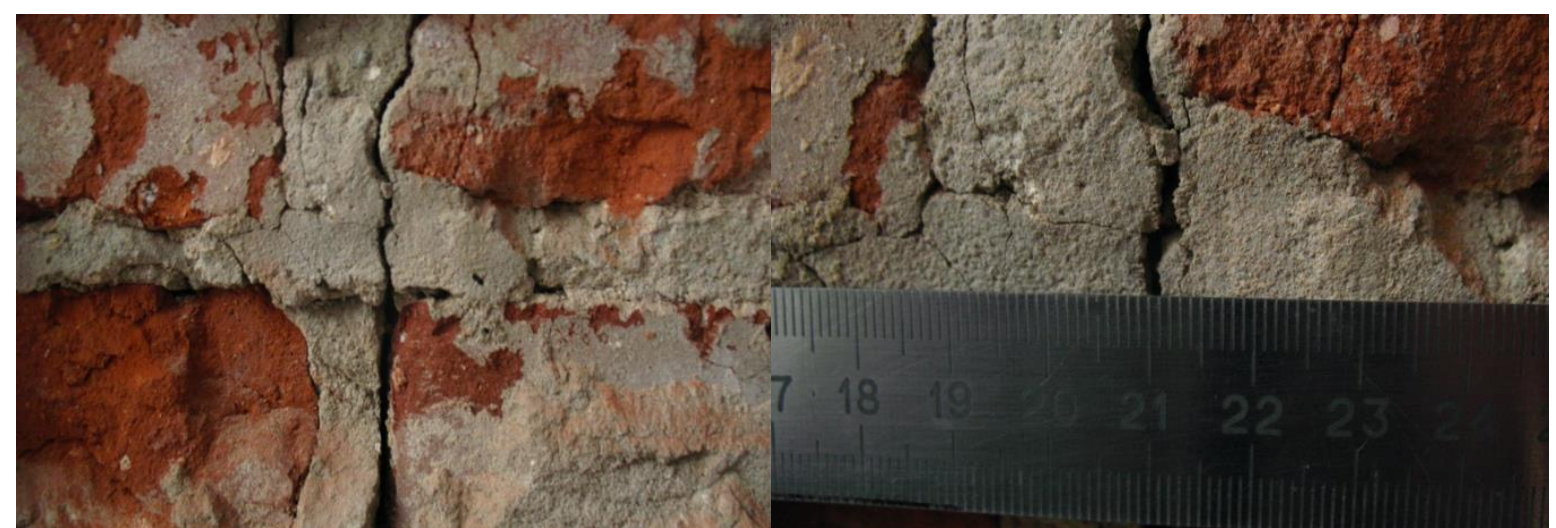

Рисунок 6- Вертикальная трещина в кирпичной кладке наружной стены. Ось 19, между осями Б-В

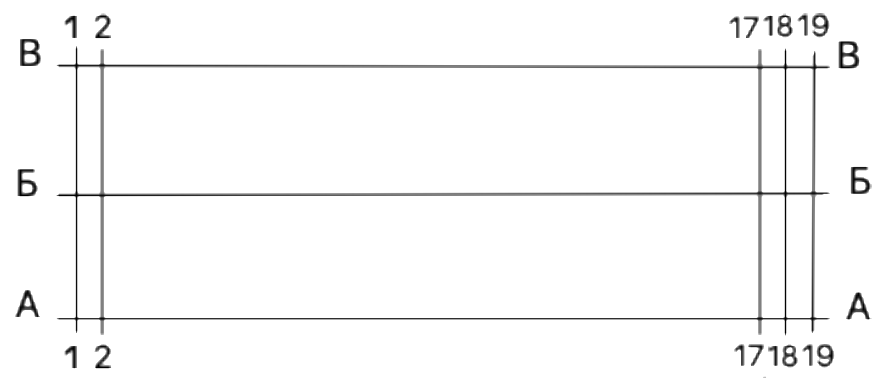

Рисунок 7- Схематичное расположение осей в здании (вид сверху)

Техническое состояние фундаментов здания, согласно ГОСТ 31937-2011 «Здания и сооружения. Правила обследования и мониторинга технического состояния», также охарактеризовано как работоспособное.

По результатам изысканий была дана рекомендация выполнить железобетонную плиту или кессон для повышения несущей способности фундаментной части торцов здания для дальнейшей безаварийной эксплуатации здания бизнес-центра.

Bblводbl:

На основе материалов, полученных при инженерных изысканиях, осуществляется разработка предпроектной документации, проектов и рабочей документации, включая, реконструкцию и ликвидацию объектов.

На каждой стадии инженерно-геологических изысканий реализуются определенные виды работ, так при реконструкции зданий и сооружений особое внимание необходимо уделить обследованию фундаментов и грунтов основания, состоянию надземных конструкций и инженерных систем, а также гидрогеологическим условиям площадки строительства.

На строительной площадке геолог отвечает только за достоверность и достаточность изысканий, генпроектировщик только за конструктивные решения, генподрядчик отвечает только за качество. Заказчик или Застройщик отвечает за все, что происходит на объекте. Поэтому геотехник нужен Заказчику для анализа грунтов, конструкций и технологий и прогноза влияния строительства на безопасность и качество объекта. 
К сожалению, многие заказчики, инвесторы и специалисты проектных, строительных и изыскательных организаций, явно недооценивая роль полноценных инженерных изысканий, пытаются снизить стоимость строительства за счет сокращения объема и состава работ, зачастую заменяя реальные изыскания изучением архивных данных. Это зачастую приводит к аварийным ситуациям, ликвидация последствий которых, значительно увеличивает стоимость строительных работ. [3]

$$
* * *
$$

1. Воробьев С.А. Специфика инженерных изысканий в современных условиях // Безопасный и комфортный город. Орел: Орловский государственный университет имени И.С. Тургенева, 2019. C. $133-136$.

2. Зыкина Н.А., Шутова О.А. Анализ видов реконстркуции жилой застройки // Современные технологии в строительстве. Теория и практика. Пермь: Пермский национальный исследовательский политехнический университет, 2018. С. 47-53.

3. Курманов А.К., Карманов А.А. Предпроектные инженерные изыскания при строительстве и реконструкции // Повышение качества образования, современные инновации в науке и производстве. Прокопьевск: Филиал Федерального государственного бюджетного образовательного учреждения высшего профессионального образования "Кузбасский государственный технический университет имени Т. Ф. Горбачева" в г. Прокопьевске, 2016. С. $140-142$.

4. Солонов Г.Г., Артеменко М.О. Реконструкция зданий и сооружений // Высокие технологии, наука и образование: актуальные вопросы, достижения и инновации. Пенза: "Наука и Просвещение" (ИП Гуляев Г.Ю.), 2020. С. 270-272.

5. СП 47.13330.2016 Инженерные изыскания для строительства. Основные положения. Актуализированная редакция СНиП 11-02-96/ http://docs.cntd.ru/document/45604554.

6. СП 446.1325800.2019 Инженерно-геологические изыскания для строительства. Общие правила производства работ /http://docs.cntd.ru/document/561027906.

\section{Захаров М.С. ${ }^{1}$, Пашкин Е.M. ${ }^{2}$ \\ Инженерная геология и инженерно-геологические изыскания: о настоящем, прошлом и будущем \\ ${ }^{1}$ Архитектурно-строительный университет (ГАСУ) (Россия, Санкт-Петербург) \\ ${ }^{2}$ Геологоразведочный университет (МГРИ) им. Серго Орджсникидзе}

(Россия, Москва)

doi: $10.18411 / \mathrm{sr}-10-04-2021-46$

\section{Аннотация}

В статье рассмотрена историческая роль Инженерной Геологии и её практических приложений в формировании и развитии геологического знания. Констатируется тот факт, что появление и развитие Инженерной Геологии ознаменовало новую ступень взаимодействия человека с геологической средой, основанную на экстенсивном расширении предметного поля научных исследований и практической работы. Приводится определение научного метода и методологической платформы, основанных на историзме, системном подходе и многоаспектном моделировании различных взаимодействий человека и геологической среды. Даны обзор основных научных достижений Инженерной Геологии советского периода и оценка современного состояния Инженерной геологии как науки и практики. Приводятся факты и анализируются причины кризисного состояния Инженерной Геологии в части науки и образования, техники и технологий, организации и управления инженерно-геологическими изысканиями. Рассмотрены недостатки и искажения принципов саморегулирования в области организации и производства инженерно-геологических изысканий. Обсуждаются сценарии выхода из кризиса на основе глобализации пространственно-временных изменений геологической среды и с учётом принципов «зелёной экономики». Указывается на необходимость создания 